\title{
Identidade e Pluralismo: Identidade Religiosa em Adeptos Brasileiros de Novas Religiões Japonesas ${ }^{1}$
}

\author{
Geraldo José de Paiva ${ }^{2}$ \\ Universidade de São Paulo
}

\begin{abstract}
RESUMO - Descreve-se pesquisa acerca dos processos psicológicos da constituição da identidade religiosa de brasileiros do sexo feminino adeptos de novas religiões japonesas. São utilizados os referenciais da teoria da identidade social e da estruturação segundo o simbólico e o imaginário. Os dados, obtidos mediante entrevistas semi-estruturadas, são apresentados sob forma de quatro relatos típicos, os quais demonstram ser a pertença grupal por via da categorização e/ou da prototipicalidade e a estruturação simbólica os processos psicossocial e pessoal, convergentes, responsáveis pela constituição da identidade. Discutese o papel positivo e negativo do sincretismo que acompanha a transformação da adesão religiosa.
\end{abstract}

Palavras-chave: identidade; identidade religiosa; simbólico/imaginário; sincretismo.

\section{Identity and Pluralism: Religious Identity in Brazilian Followers of Japanese New Religions}

\begin{abstract}
A research about the psychological processes of religious identity constitution of female Brazilian followers of Japanese new religions is here described. Social identity and structural theories are focused, according to the symbolic and imaginary. Data, obtained through semi-structured interviews, are presented under the form of four typical reports, which show that group belonging by categorization and/or prototypicality and symbolic structuration are the convergent psychosocial and personal processes responsible for the constitution of religious identity. Positive and negative aspects of syncretism that follows the religious adhesion transformation are discussed.
\end{abstract}

Key words: identity; religious identity; symbolic/imaginary; syncretism.

A discussão da identidade se desdobra, na Psicologia, em duas direções: a da identidade pessoal e a da identidade social ou grupal (Cassidy \& Trew, 1998; Frable, 1997; Ellemers, Spears \& Doosje, 2002). A identidade grupal conhece atualmente um desenvolvimento notável: a fértil qualificação hodierna das identidades políticas, profissionais, religiosas, étnicas, de gênero e outras, aponta para a dimensão psicossocial da identidade, isto é, para a pertença da pessoa a um grupo político, profissional, religioso ou outro. A perspectiva aqui adotada é psicossocial, porém atenta à peculiaridade dos indivíduos e à construção pessoal da identidade segundo o eixo do simbólico ou do imaginário. Ocupamo-nos da identidade religiosa em vias de formação, ou de transformação, a saber: quando a pessoa deixa de aderir a um grupo religioso e adere a outro e quando opera uma transformação profunda ou superficial de sua definição religiosa. Como no mundo das representações psíquicas, as rupturas e adesões raramente se dão por completa exclusão do contrário, haverá ocasião para se examinar a adesão grupal e a transformação profunda ou superficial da identidade associadas ao sincretismo. De fato, é particularmente na área da religião que o termo se faz presente.

A transformação da identidade religiosa será examinada nas histórias de pessoas que deixaram uma confissão

1 Projeto de pesquisa apoiado pelo CNPq.

2 Endereço: Universidade de São Paulo, Instituto de Psicologia, Av. Prof. Mello Moraes, 1721, São Paulo, SP, Brasil, 05508-900. E-mail: gjdpaiva@usp.br religiosa, geralmente a católica, e aderiram a uma 'nova religião' japonesa, isto é, uma das numerosas religiões que surgiram no Japão à margem do xintoísmo e do budismo (Matsuno, 1974; Murakami, 1980) e, mesmo, do cristianismo (Miyazaki, 2000; Reid, 1991). Ao Brasil aportaram, a partir da década de 50, várias dessas 'novas religiões' destinadas inicialmente aos japoneses e descendentes, mas, em décadas recentes, voltadas para a população em geral. Atualmente, em seus quadros intermediários, contam com brasileiros de ambos os sexos sem ascendência japonesa e têm a maioria dos seguidores igualmente sem aquela ascendência. Estudase aqui o percurso desses brasileiros de uma religião anterior, geralmente a católica, para a Perfect Liberty ou para a Seichono-iê. A escolha de brasileiros sem ascendência japonesa e de origem cristã, que passaram a membros dessas duas congregações, deveu-se ao entendimento de que constituiriam casos interessantes para o estudo da transformação da identidade psicossocial, uma vez que supõe o trajeto entre dois universos sócio-culturais assaz distintos, trajeto demarcado pela migração grupal e pela elaboração pessoal.

\section{Teoria da identidade social}

Nosso ponto de referência será a teoria da identidade social de H. Tajfel $(1972,1978)$ e J. C. Turner (1984; Oakes, Haslam \& Turner, 1998; Turner \& Oaks, 1986) da Escola de Bristol. Essa é uma teoria voltada para a análise das relações, conflituosas ou não, entre os grupos. A identidade resulta da tomada de consciência de se pertencer a um grupo e de não 
se pertencer a outro. Essa tomada de consciência realiza-se pela categorização, critério que discrimina os grupos como próprio e alheio, (ingroup e outgroup), e localiza o individuo no grupo próprio. Como motivação subjacente ao processo de categorização, Tajfel postula a auto-estima: para adquirila ou mantê-la, a pessoa se engaja na comparação entre os grupos, o que lhe permite construir seu grupo como superior aos grupos dos quais, "pré-reflexivamente", não faz parte e a que, reflexivamente, passa a não pertencer. A pessoa pertence a vários grupos discriminados por categorizações diferentes e tem, por isso, múltiplas identidades. Conforme se mostrarem capazes de confirmar, diminuir ou negar sua auto-estima, a pessoa tenderá a manter-se nesses grupos, eventualmente modificando-os, ou então procurará reduzir sua participação ou mesmo se afastar.

Turner propõe como base do processo de categorização, ao invés da motivação afetiva da auto-estima, uma motivação cognitiva, que conduz ao estabelecimento do protótipo do grupo. O protótipo substitui o que a lógica clássica denominava de conceito, preferindo a descrição do objeto por meio de características percebidas como discriminativas. Prototipicalidade é o critério cognitivo pelo qual coisas ou pessoas são colocadas juntas num grupo e separadas de outros agrupamentos. Como prototipicalidade é uma entidade elástica, a pessoa pode comparar-se com o protótipo, comparar umas com as outras as pessoas que partilham do protótipo, comparar-se a si mesma com as outras pessoas e, finalmente, comparar-se consigo mesma em relação ao protótipo em diversos momentos de sua pertença ao grupo. Essa ultima comparação denomina-se autoprototipicalidade. Em relação à identidade pessoal, essa derivação teórica acentua a perda da identidade pessoal em benefício da identidade grupal.

\section{O simbólico e o imaginário como eixos da construção pessoal da identidade}

A consciência de uma dimensão pessoal na construção da identidade está presente em quase todos os teóricos da identidade psicossocial. Apenas Turner opõe correlativamente identidade pessoal e identidade psicossocial, na contra-mão da corrente contemporânea de investigação da identidade que, mesmo na Sociologia, está atenta às trajetórias individuais do processo de formação da identidade (Hervieu-Léger,1998; Negrão, 1997). Paiva e colaboradores (Paiva, 1999; Paiva \& cols., 2000) têm explorado a peculiaridade da construção pessoal da identidade com os conceitos, de inspiração lacaniana ((Kaufmann, 1993; Lacan, 1966; Laplanche \& Pontalis, 1995), de imaginário e de simbólico. O imaginário diz respeito ao estágio do espelho (Lacan, 1966), quando a criança de poucos meses começa a constituir-se a partir de sua imagem especular e inicia relações nas quais ela e o outro são percebidos como réplicas. Nesse estágio, o ego é um outro e o outro um alter ego (Laplanche \& Pontalis, 1995). Característico do imaginário é reduzir o outro ao mesmo, o diferente ao igual, o estranho ao conhecido, e nutrir-se de sinônimos, homologias, metonímias e isomorfismos. O simbólico diz respeito à interdependência dos significantes, ou seja, ao encadeamento de significantes, segundo o qual, cada significante adquire sua função ao entrar numa ordem exterior, de tal modo que, embora possa permanecer o mesmo como elemento, torna-se outro quando incluído em outro encadeamento (Kaufmann, 1993). O simbólico transita, assim, pela diferença, pela alteridade, pela metáfora, e produz um significado novo. Imaginário e simbólico organizam a vida psíquica sob aspectos diferentes e uma vez constituídos no psiquismo mantêm-se íntegros e com funções complementares. Aplicados ao estudo das transformações da identidade religiosa, a predominância do imaginário indicará a manutenção essencial da referência religiosa anterior, com o acréscimo, por assimilação, de elementos da nova referência; a predominância do simbólico indicará a substituição do sistema anterior por outro sistema, com a possível manutenção de elementos do primeiro inseridos na nova ordem de significação. $\mathrm{O}$ emprego desses conceitos permite discernir se a trajetória da adesão religiosa acaba deixando a pessoa no mesmo lugar ou conduzindo-a para outro. Sugere-se que a transformação da identidade se realiza em sentido próprio apenas no simbólico. Se se realizar no imaginário, haverá apenas a expansão da mesma identidade por meio de novas imagens da mesma fé.

\section{O sincretismo como fautor de transformação da identidade}

A avaliação do sincretismo como amálgama religioso tem sido desfavorável entre os estudiosos, a ponto de perder quase todo interesse analítico (Stewart \& Shaw, 1994). Testemunha-se, contudo, hoje a tentativa de revalorização do conceito como processo pelo qual o encontro de culturas tende a modificar as respectivas crenças, inclusive as religiosas. Com referência ao desenvolvimento do cristianismo, Hoornaert (1995) observa que desde cedo se compôs com o pensamento judaico, grego e latino e, mais tarde, com o germânico. Em outro extremo da cultura, pode-se acompanhar o esforço de um repensar japonês do cristianismo, na obra literária de Endo Shusaku (Paiva, 2001). Esse processo de transformação de crenças tornou-se potencialmente mais intenso com a "mundialização" da cultura. A "mundialização" vem propondo questões epistemológicas agudas, como as das relações entre pós-modernidade e pré-modernidade e da "declinação plural" da religião (Sanchis, 2001). Ainda assim, o termo sincretismo não supera toda a hipoteca negativa e nem adquire, sem mais, uma densidade analítica. Estamos, contudo, com os que vêem nas trocas culturais oportunidades para novos insights que favorecem a expansão da personalidade, a tolerância entre os grupos e a diversidade de modos humanos de ser (Stewart \& Shaw, 1994).

\section{Duas novas religiões japonesas no Brasil: a PL e a Seicho-no-iê}

A instituição religiosa Perfeita Liberdade ou PL (Perfect Liberty) ressurgiu no Japão em 1946, com Tokuchika Miki, e chegou ao Brasil em 1957. Sua substância doutrinária consiste na pessoa de Oshieoyasamá e nos 21 preceitos revelados, dos quais o primeiro é "vida é arte" e os demais se referem à sinceridade e dedicação, à criatividade e à espontaneidade, à gratidão. É na expressão plena da personalidade de cada um, a "perfeita liberdade", que se cumprem os preceitos. 
Oshieoyasamá é o "sempre atual fundador" da PL porque, em virtude de sua união singular com Deus, recebe a iluminação apropriada para cada época; é para ele que são endereçados os pedidos de orientação (mioshiê) frente às advertências divinas (mishirassê) de difícil interpretação; é em união com ele que se realizam as preces, em particular a poderosa prece oyashikiri; é dele que os mestres mais elevados retiram a competência espiritual; é para ele que são transferidos mensalmente os males do mundo, que ele transfere para Deus. Nas dificuldades, o adepto pede ao mestre, responsável pela igreja local, orientação prática para, inclusive, eliminar o vício espiritual, próprio ou dos antepassados, origem da dificuldade. A eliminação do vício implica ações em prol do próximo e oferta em dinheiro, hoshô. O emblema da PL é o omitamá, forma circular que tem no centro o sol, donde emanam 21 raios, indicativos dos Preceitos.

A Seicho-no-iê (S), fundada em 1930, chegou ao Brasil por volta de 1950. O fundador, Masaharu Taniguchi, recebeu a revelação de que "nada existe de matéria: só existe o Jissô, traduzido geralmente por verdade, realidade, espírito, eu verdadeiro ou Deus (Murakami, 1980, p. 80). A revelação se desdobra em alguns ensinamentos: o homem é por natureza, filho perfeito de Deus; pecado e doença são sintomas de distorção nessa relação, mas não têm realidade em si mesmos; no plano do Jissô, o homem é perfeito, mas no plano do fenômeno, ilusão e efeito físico da causa mental, é atingido pelo pecado, pela morte e por vários infortúnios; a cura dos males está no retorno ao Jissô. O agradecimento é central na doutrina e no culto. A religiosidade é pontuada pelas reuniões dominicais, com prece meditativa, recitação de sutras, testemunhos de vivências e palestra; pelo culto dos antepassados, pela purificação do subconsciente e por práticas de aprimoramento espiritual, com destaque para a meditação Shinsokan. A Seicho-no-iê (S) tem como emblema um círculo constituído pelo sol, pela lua e por uma estrela, que representam o xintoísmo, o budismo e o cristianismo. A relação com o cristianismo, ao menos no meio brasileiro, é realçada pela figura do Cristo da Seicho-no-iê e pela recitação do Pai-nosso.

\section{Método}

\section{Sujeitos}

Dezoito adeptos da PL e vinte da S, jovens e adultos do sexo feminino, brasileiros sem ascendência japonesa, originalmente não filiados, com pelo menos três anos de filiação à nova religião, não ocupantes de cargo hierárquico.

\section{Instrumento e procedimentos}

O instrumento consistiu de uma entrevista semi-estruturada, conduzida por duplas de entrevistadores, psicólogos formados ou em formação em local e horário previamente agendados. A entrevista foi gravada com a aquiescência dos entrevistados. O roteiro de entrevista incluiu os itens seguintes: a religião do entrevistado, a religião anterior, como chegou à religião atual, o que não encontrava na religião anterior, o que encontrou em sua nova religião, quais os atos mais importantes do culto e do ensinamento da religião atual, que palavras emprega para se referir à nova religião, que pessoas considera exemplares da nova religião, qual a possibilidade de pertencer, ao mesmo tempo, à nova religião e a uma outra, o que conserva da religião anterior.

\section{Análise dos resultados}

O teor das entrevistas foi considerado no seu valor de face, uma vez que a pesquisa se desenvolveu no nível da cognição e se pode supor nos sujeitos, dado seu envolvimento religioso, suficiente conhecimento e honestidade de informação. Aceitou-se o entendimento de Mucchielli (1991), segundo o qual a aceitabilidade de sentido dos dados qualitativos estará suficientemente assegurada se a interpretação for coerente e permitir uma compreensão global do fenômeno e se a interpretação proposta puder ser compartilhada por outros estudiosos.

\section{Resultados}

A seguir, são apresentadas, resumidamente, quatro entrevistas a título de ilustração dos vários processos de transformação da identidade religiosa: mudança consumada de pertença grupal e de simbólico, mudança em curso de pertença e de simbólico, pertença a mais de um grupo e acréscimo de mais um simbólico, ambigüidade de pertença e de simbólico. Cada entrevista é seguida de comentário à luz da teoria da identidade social e dos conceitos de imaginário/simbolico.

\section{1) Mudança consumada de pertença grupal e de simbólico}

PL 1 é adepta da PL há 12 anos. Sua religião era a católica, que descobriu ser abstrata em comparação com a PL, "presente na vida da gente, todo momento, com o Mestre para dar orientação, com a prece de oyashikiri para qualquer problema. Por isso mudei”. De diferente na PL, "os pequenos ensinamentos que servem pro dia-a-dia, nada de genérico, como na Igreja católica. $O$ abstrato "amai-vos uns aos outros'é substituído pelo 'felicite a si e ao próximo' da PL". Conhece bem o culto, a prece matutina e noturna quotidiana e o lai-hai, missa dominical; domina o vocabulário: mioyaookami (Deus), oyashikiri ("palavra que só tem na PL, sem tradução"), shikiri de Oshieoyasamá (bênção do Patriarca), omitamá, onde estão entronizados Deus, os fundadores da PL e os antepassados. A grande diferença da PL em relação às outras religiões é "ensinar que a melhor preparação para uma outra vida eventual é ser feliz e praticar o bem agora". Outra diferença é o patriarca:

Oshieoyasamá é uma obra divina, pessoa escolhida por Deus, como se estivesse no estado espiritual uno a Deus, mas não é Deus. Há um Oshieoyasamá para cada época, pois um dos preceitos é: tudo progride e se desenvolve, inclusive o ensinamento. No dia 21, tem-se o ato sagrado de purificação de Oshieoyasamá, que recebe no corpo dele, na pessoa física do mestre Takahito Miki, todos os problemas dos adeptos; ele se responsabiliza com o corpo dele a salvar os adeptos; então ele oferece o próprio corpo dele a Deus pra gente ser salvo. Toda 
vez que a gente tem um problema, vai na igreja e recebe a prece de oyashikiri. Oshieoyasamá recebe aquilo no corpo dele. E ele vai acumulando aquilo o mês todo. Então, todo dia 21, ele devolve a Deus essa responsabilidade e aí ele fica renovado, pra durante mais um mês poder salvar os adeptos. Mas ele se responsabiliza por nós, desde que a gente se comprometa a praticar os ensinamentos. Cada momento é obra divina, uma arte, e a gente, tendo auto-expressão correta, artifica aquele momento.

PL1 exemplifica o que é artificar: como a família ia mudar-se, foram aconselhar-se com o mestre, que lhes disse:

\begin{abstract}
Vamos artificar. Imagina como se já tivesse o apartamento vazio, já realmente concretizou a venda, já estão mudando". Então, a gente já está colocando tudo nas caixas, desmontando a mesa, esvaziando. A gente estava esperando vender pra começar a mexer. Mas a gente já está fazendo arte: já tá movimentando, já começamos a encaixotar um monte de coisas, já começou um monte de gente a ligar. Uma coisa ao redor da qual a PL, toda a filosofia, tudo gira, uma coisa que realmente só a PL tem, é a advertência divina, mishirassê, e a correção desses problemas, mioshiê. Quando se tem um vício espiritual, Deus adverte com o mishirassê. Mioshiê é o esclarecimento de onde se está errando. Doença, acidente, infortúnio, isso é mishirassê. $O$ mishirassê não é castigo, como na católica onde, se comete pecado, a pessoa é castigada. Na PL, se você errou, Deus vai te advertindo pra você não errar mais, é uma orientação. Nunca ouvi falar de nenhuma outra religião que tenha essa verdade: esse é o ponto diferencial.
\end{abstract}

O exemplo de PL1 é Oshieoyasamá, que "consegue aceitar tudo como obra divina e não se deixa levar pela emoção da raiva". Exemplo, também, é a mestra local que leva uma vida de renúncia e está sempre de "bom-humor, pronta a te atender de coração aberto e de portas abertas". PL1 conhece

várias pessoas que são da PL e vão à missa, vão em outras religiões. Mas se você segue só a PL, que é o meu caso, eu acho que é melhor; você evita de estar dividido entre uma coisa e outra. Se você vai numa linha reta, você chega mais rápido. Mas nada é proibido: quem quiser pode freqüentar qualquer outra religião.

Da religião anterior, PL1 diz que "conservou tudo, porque o ensinamento é o mesmo, mas mudou a visão: pensa em ser útil ao próximo e não simplesmente em amar a Deus e ao próximo, aqueles Dez Mandamentos, que as pessoas ouvem e não praticam." Vai à igreja católica para um casamento, uma missa especial":

Mas não ficou muita coisa de forte, de marcante. Deixei umas coisas de lado e vieram outras coisas novas: elas são as mesmas coisas, só que eu ajo de forma diferente. Se pudesse, pra mim o mundo todo seria peelista, mas cada um tem a liberdade de aceitar ou não.

Pensa, como a Mestra, que "todas as religiões vão se unir, mas sem se tornarem uma só".

\section{Comentário}

PL1 mudou o ingroup, do católico para o da PL. Referese à religião católica como religião anterior e contrapõe-se a peelistas que vão a outras religiões; declara, formalmente, que da religião católica não ficou muita coisa de forte e de marcante e que, no lugar de coisas deixadas de lado, vieram outras, novas. A pertença ao grupo da PL se revela na freqüentação das atividades e no contato com os mestres. PL1 demonstra ter mudado de simbólico religioso, que apresenta bem articulado, possuidora que é do protótipo peelista: a pessoa e a função de Oshieoyasamá, os ensinamentos e preceitos, a prece, a orientação dos mestres, a dedicação na construção da arte na vida de cada dia. Persistem elementos católicos, como a referência à missa dominical, aos Dez Mandamentos e ao "amai-vos uns aos outros", ao caráter punitivo dos infortúnios, que comparecem, sem destaque, na nova articulação simbólica e podem ser caracterizados como imaginários. Se PL1 manifesta consciência nítida do protótipo da PL, não parece encarná-lo em algum modelo pessoal, a não ser sob o ponto de vista do controle da ira (Oshieoyasamá) e da disponibilidade para a acolhida (a mestra local).

Na dimensão da prototipicalidade, compara-se vantajosamente com outros membros da PL, que freqüentam outras religiões. Verifica-se, na trajetória de PL1, uma conversão, pois houve a substituição de um simbólico religioso por outro bem delineado, com poucos elementos do simbólico anterior transformados em elementos imaginários. Confirma-se a convergência dos processos de formação da identidade pessoal e da identidade psicossocial, no sentido de que a pessoa tem consciência de ser religiosa no grupo religioso de filiação.

Finalmente, a identidade religiosa atual de PLl pode ter sido construída a partir da identidade católica com a transformação de elementos dessa identidade, enquanto os mandamentos se tornaram mais concretos e os males da vida passaram a ser advertências divinas em vez de simples castigos. Essa integração imaginária parece ir em direção ao sincretismo, entendido como um desabrochar religioso pessoal de PLl, que passa a entender e a praticar de maneira efetiva orientações religiosas que não exerciam impacto em sua vida pessoal.

\section{2) Mudança em curso de pertença e de simbólico}

PL4 é adepta da PL há 14 anos. De família católica, "sempre se identificou" com a Igreja, mantendo contato com padres, freiras e seminaristas e fazendo retiro espiritual. "Mas, eu buscava alguma coisa a mais, não tinha respostas para os questionamentos, para as dúvidas, para as coisas do dia-a-dia". A PL surgiu naturalmente dos encontros com uma amiga que lhe mostrou como a PL respondia exatamente a suas questões. PL4 repete que na religião católica não tinha respostas para "o porquê das coisas, o porquê de ser assim e não diferente. Ouvia falar de carma, mas isso já não é da católica, já vem lá do espiritismo.” Na PL está percebendo "os vícios que tem, as correntes da família”. PL4 está saindo de um processo depressivo grave, graças à dedicação, makoto, aos outros:

na PL você aprende a se doar, a ser útil ao próximo, numa visita de amor, numa oração, numa atividade na igreja, onde 
você vai limpar o banheiro para felicitar as pessoas, ou fazer um almoço, ou arrumar a igreja.

O ensinamento da PL é esse: "o de artificar o dia-a-dia, felicitando as pessoas ao redor, mostrando o lado positivo das coisas". PL4 detalha em sua vida o ensinamento da PL de que tudo é obra divina, ou graça: foi preciso chegar à separação para perceber os pontos em que estava falhando. Hoje, o próprio ex-marido está se formando para mestre: "ele também passou pelas dificuldades de entender, mas hoje está praticando, está em outro estado, está feliz e se encontrou". Além do preceito "vida é arte", PL4 considera importantes: o missassaguê (serviço); o makoto (dedicação) e o hoshô (oferta em dinheiro). A palavra que considera expressiva e dotada de força é oyashikiri, "palavra que salva, palavra forte realmente". Indagada se as pessoas podem participar da PL e ter uma outra religião, responde:

Perfect Liberty! Tudo pode! A PL não proíbe nada. Depois, com o tempo, você vai ver que ela acaba te completando, mas não é proibido nada. Tem pessoas que a gente conhece que é da PL,e católico, ou de outra religião, nada que se proíba. Todo o tempo que tenho livre eu dedico à PL, realmente. Aqui eu consigo praticar tudo aquilo que eu estou buscando; na católica, sem nenhuma restrição, mas eu vou lá só pra assistir uma missa, ouvir palavras também que são palavras de ensinamento; mas eu só vou ouvir, não posso ficar praticando nada do que eu aprendi ali no momento.

Finalmente, comenta algo bem pessoal, que a PL lhe fez ver: ela percebe que suas "desvirtudes vêm realmente da parte da família, [católica, não praticante], aquilo de você ir à missa, você ouviu e dali pra frente não consegue colocar em prática o que ouviu".

\section{Comentário}

PL4 fala de religião católica e de filosofia de vida da PL, com o que aponta aparentemente para simbólicos de ordem diferente. A distinção é confirmada pela contraposição do espiritismo ao catolicismo e de ambos à PL. Ela comenta, também, o paulatino distanciamento do grupo católico em direção ao grupo peelista e a concomitante mudança do simbólico religioso. De fato, sua referência atual é o protótipo peelista: a pessoa e a função mediadora de Oshieoyasamá, as cerimônias rituais, a palavra de salvação oyashikiri, os preceitos e as práticas relativas à elaboração artística da vida, o caráter de espelho do individuo, que reflete as falhas e vícios da família, em direção tanto aos antepassados como aos descendentes. PL4 indica Oshieoyasamá e alguns mestres como modelos, mas não chega a medir-se a eles na determinação de quão prototípica ela própria é.

A referência de PL4 ao catolicismo no decorrer da entrevista não é espontânea e restringe-se à missa, à inoperância do ensinamento católico e à influencia negativa da família católica. PL4 parece não conservar da antiga religião nenhum elemento que se possa considerar da ordem do imaginário, assimilada ao simbólico peelista. Nesse contexto, tampouco se pode falar de uma construção positiva sincrética de sua identidade religiosa pessoal ou psicossocial, confirmando-se a convergência dos processos individuais e psicossociais de formação da identidade.

\section{3) Pertença a mais de um grupo e acréscimo de mais um simbólico}

PL3 está filiada à PL há mais de quatro anos. Indagada da religião, responde: "a principal é a católica, não deixo de ser católica, mas mesmo assim eu me identifiquei muito com a PL". Vai "vez ou outra na igreja" [católica], mas participa "muito mais aqui que na religião católica". Chegou à PL por meio de um amigo. Sempre sentiu " um vazio muito grande e depois da separação achava que precisava dar muito mais de mim para alguma coisa". Na PL, tem contato com diversas pessoas e outra cultura, "e isso, eu acho que engrandece muito a pessoa". Ao comparar a PL com a religião católica, afirma ter encontrado:

mais proximidade, reuniões freqüentes e muita ligação com outras pessoas. Isto eu nunca vi numa igreja católica. Você sempre encontra uma palavra, alguém que possa entender, calor humano muito maior do que em qualquer outro lugar. Uns contam para os outros sua vivência e isso abre bastante a cabeça.

PL3 menciona as práticas cultuais importantes, as práticas normais do ano e pondera:

O fundamento dos ensinamentos é o de que tudo é arte na vida; para sair de um problema, a pessoa deve artificar [sic]; em tudo você vai procurar artificar". [...] Exemplo na PL? acho que não existe um modelo de pessoa, eu vou pegando o que é melhor para mim; no catolicismo se tem o papa, na PL isso não existe, e é por isso que é Perfeita Liberdade!

Em relação a outras religiões, explica "aqui ninguém te proíbe de nada, muito menos de religião. Livres, você faz umbanda, mesa branca, espiritismo". Entre PL e outras religiões, não vê conflito: "Tranqüilo. Mas nada de fazer a cabeça: não posso fazer isso porque a PL não quer. $E$ realmente uma vida muito livre, livre arbítrio, você sabe o que faz e acabou".

No dia-a-dia e na aflição, "eu sempre recorro à $P L$, ou à prece da PL”, diante do omitamá doméstico, que é um:

símbolo santificado, como se fosse um crucifixo na católica. Uma diferença com a católica é que na PL, se você passa por qualquer problema grave, de saúde, ou um acidente, pede orientação aos mestres e eles fazem uma solicitação para saber por que aconteceu aquilo. A resposta não é o óbvio: sofri um acidente porque não prestei atenção. Mas porque você não prestou atenção? É isso que a PL te indica. A PL abre novos horizontes pra gente; você percebe que aquele problema não é só teu: esperança, fé, que um dia aquilo vai ser resolvido. Eu entrei na PL, em busca de solução para um problema; até hoje não consegui, mas se não tivesse a ajuda da PL, não saberia dizer o que teria acontecido comigo. Já tem quatro anos. Provavelmente se eu não tivesse a PL naquela época, eu teria desistido de tudo, sei lá, não estaria talvez nem aqui agora. É uma força muito grande. 


\section{Comentário}

PL3 filia-se com seriedade ao grupo PL, que aparentemente não entra em competição com a religião católica, à qual diz continuar pertencendo. Destaca na PL o engrandecimento pessoal, resultante do contato pessoal e cultural, e a ausência de qualquer pressão relacionada com a filiação religiosa. Parece relacionar-se com a PL como grupo de natureza não religiosa, de grande influência em sua vida pessoal e social. A entrevista sugere que PL3 não substituiu o simbólico religioso anterior por outro simbólico religioso. Antes, parece ter acrescentado ao simbólico religioso católico um simbólico de outro tipo, tanto que não contrasta, a não ser superficialmente, o catolicismo e a PL. Atravessa uma fase de fragilidade emocional e encontrou um grupo social que a ocupa, a distrai, a enriquece culturalmente e lhe dá um apoio cognitivo e afetivo. Para PL3, o simbólico da PL está relativamente estruturado, pois ela tem como protótipo peelista o culto pela paz e pelo agradecimento, inclusive aos antepassados, a elaboração artística da vida cotidiana, o omitamá, a prece e a explicação dos infortúnios da vida. Enfatiza a liberdade da PL frente às opções religiosas e a inexistência de pressão sobre a pessoa. Desse conjunto de expressões, fica a forte sugestão de que PL3 pertence igualmente a dois grupos, cada qual com seu simbólico, o de um grupo de apoio social eficiente e estruturado e o de um grupo religioso. Há declarações ambíguas, relacionadas com um e outro simbólico: a comparação do omitamá com o crucifixo, ambos símbolos santificados; a ausência, na PL, de um modelo obrigatório, como o papa, a sinonímia dos benefícios com as graças divinas. Mas, são declarações insuficientes para se falar em migração de elementos de um simbólico para outro sob forma do imaginário.

Nesse contexto, a negação de um depositário das características da PL e a referência inevitável ao papa no catolicismo, confirma a manutenção de dois simbólicos de ordem distinta e, aparentemente, a menor estruturação do simbólico peelista, em relação ao qual PL3 não mede sua autoprototipicalidade. Não surpreenderia que na vivência religiosa católica, PL3 possa ter desenvolvido uma identidade beneficiada pelas contribuições, de índole terapêutica, da pertença à PL, embora o contexto da entrevista não tenha sido de molde a elucidar essa possível influência. Teríamos, então, o resultado de uma construção positiva da identidade religiosa com elementos, não exatamente de outra religião, mas de um grupo social com cultura peculiar. Seria um caso de construção sincrética, embora não de composição sincrética religiosa.

\section{4) Ambigüidade de pertença e de simbólico}

S15, de origem católica, teve contacto com a S, em aguda crise espiritual. Retirando-se para o quarto, à espera da morte, encontrou uma "revistinha sem capa, e passei três dias sem dormir, sem comer quase, naquele êxtase de conhecimento que eu estava colhendo daquela revistinha. E comecei a sentir que eu tinha uma nova resposta". Na academia, reencontrou o mesmo emblema da $\mathrm{S}$ e conseguiu o endereço do local de reuniões. Lá ouviu uma "professora falar da importância de não viver uma vida mundana e sim uma vida séria". S15 reconhece que vivia muito para a matéria, para o corpo, para a carne, praticando coisas erradas, e até um aborto. De uma outra preletora ouviu que "se houvesse arrependimento sincero, a pessoa teria condição de uma salvação interior, de um contato com esse seu Deus interior". Tomou a decisão de mudar de vida. Compara a vida mundana a uma droga e diz que para sair dela a pessoa sofre: "eu sentia as pernas duras, tanto foi forte aquela força de energia negativa me chamando para a vida mundana". Diz que saía para a rua para se conscientizar e ter força e "dominar esse cavalo, esse corpo, esse casulo". Quando decidiu mudar de rumo e de cidade, viu-se grávida e queria abortar de novo, pensando que se Deus misericordioso lhe tinha perdoado o primeiro aborto, iria perdoar-lhe também o segundo, pois não tinha condição de começar uma nova vida, numa cidade grande e desconhecida, com uma criança. Nesse momento, recebeu o conselho de um amigo que "falou coisas para mim como se fosse Deus Komioshi, que é o Deus que trabalha através da S, é o anjo Gabriel, vamos dizer assim, o anjo Miguel, aliás".

Com coragem foi para a cidade grande, e de avião, "porque a S tem a tendência de nos ensinar a tirar tudo do nada, e você sonhar alto". A passagem de avião apareceu. Então, S15 "tomou consciência de que sua religião seria a S e de que todas as religiões são a mesma verdade, porque existe um só Deus". Pensa que à religião católica "não faltava nada", mas ela "não tinha despertado a consciência do mal que estava cometendo". Graças à S, passou a entender a influencia da vida carnal do pai e do avô, "sua família cármica". Tendo "abraçado" a S, vive uma "vida de missionária", fazendo faxina e limpeza de banheiros de residências, escolas e parques, e repetindo sempre "muito obrigada". Mesmo abraçando a S, S15 continua católica, pois a pessoa é orientada a "respeitar sua origem, católica, protestante, umbanda, o que for". Reafirma que a $\mathrm{S}$ "não é bem uma religião, mas uma filosofia, que faz você entender melhor sua religião de origem e as outras religiões".

Continua mandando celebrar missa pelos antepassados e pelos vivos da família, continua a ir à igreja, embora na $\mathrm{S}$ haja mais celebrações de culto pelos falecidos. Diz que a igreja católica dá boa base para a vida e que sua família era católica praticante, ligada a padres e freiras. Acredita que

graças a essa base é que eu pude alcançar [a Seicho-no-iê], porque para mim, a $S$ é a maior das faculdades do universo; eu acredito que a Igreja católica foi como um segundo grau, e a partir daí fui crescer numa faculdade de verdade, faculdade da vida, através da filosofia.

Atribui essa abertura à cultura oriental que recebeu da $\mathrm{S}$, passando-lhe "consciências que jamais teria" em sua formação "ocidental, com certos dogmas, certos tabus". E decidiu que essa seria sua ultima religião. Conserva do catolicismo o "hábito da oração", não mais como "uma pecadora miserável, mas como um ser divino, uma filha de Deus". Explica que o básico na $\mathrm{S}$ é acreditar que é filha de Deus.

Filho de gato, não é gatinho? E peixe? Efilho de Deus, é o que? Será Deus? A S jamais diz a alguém que é filho de pecador, ou pecador: você nunca pecou, na essência divina você sempre foi perfeito. Para limpar o subconsciente das impurezas do 
passado existe a meditação shinsokan, cuja base é a leitura da sutra sagrada; são quatro sutras, que têm quatro mantras bem fortes. Há também a prática da maratona: passar vinte e quatro horas lendo o livrinho das sutras, direto, vai e volta, volta e vai: isso dá uma harmonia interior e faz fluir melhor a consciência divina.

Para S15, o sutra sagrado é "o resumo da Bíblia, do Bagavagita, de todos os livros sagrados". Também importantes são "o perdão e o agradecimento". Tão importante é o agradecimento que há uma prática de dizer dez mil vezes 'obrigado' por dia, ou até mais. S15 acredita que

na nova era do milênio não haverá mais a questão da minha religião católica, Legião da Boa Vontade, religião não sei o quê, Hare Krishna: é a era do amor. Todos vão caminhar para o mesmo vertical, Deus, só isso: luz, energia. As religiões são todas escolas que permitem desabrochar o nosso interior, esse Deus lindo e maravilhoso, essa divindade que existe dentro da gente.

Pessoas exemplares da S são o Mestre Taniguchi e sua esposa, professora Teruko, mestres espirituais desencarnados. Entre os "mestres espirituais encarnados", cita professores ou preceptores, um deles idoso, "catedrático na nossa teologia", que está "partindo para o mundo espiritual, que é como se diz na S". S15 aponta como sua "libertação gigante" a quebra do ego do orgulho e da luxúria por meio de serviços humildes e de um possível trabalho com prostitutas.

\section{Comentário}

S15 não abandonou o grupo católico e faz parte do grupo da $\mathrm{S}$, mas revela-se indefinida quanto ao simbólico de cada grupo, o que confere ambigüidade a sua identidade religiosa e não permite, no momento, um ajuizamento de seu processo de transformação de identidade. Com efeito, S15 tem o protótipo da S: a inexistência do pecado, a filiação divina perfeita, o Deus interior, a purificação do subconsciente pela leitura dos sutras/mantras na meditação shinsokan, o corpo como casulo do espírito, o carma dos antepassados, o agradecimento constante. Como protótipos pessoais cita o casal Taniguchi e destaca um "catedrático da teologia". Decidiu-se pela $\mathrm{S}$ como religião, aliás sua última religião, e além das práticas devotas da $\mathrm{S}$ apresenta sua autoprototipicalidade de missionária, dedicada a serviços humildes para o bem das pessoas, inclusive ao trabalho com prostitutas. Em outros momentos, fala da $\mathrm{S}$ não como religião, mas como filosofia que faz compreender melhor a religião de origem. De outra parte, afirma que continua católica, continua a ir à igreja e a mandar celebrar missas, uma vez que a $\mathrm{S}$ orienta as pessoas a respeitar a origem, no caso, a religião católica.

S15 parece, então, considerar o catolicismo como religião de base, subsumida atualmente pela $S$ e que tende, na Nova Era, a ser juntamente com as outras religiões absorvida no mesmo vértice, simplesmente Deus como luz e energia interior. Ao redor de cada simbólico circulam elementos do simbólico complementar: em volta da $\mathrm{S}$ encontram-se os anjos Gabriel e Miguel, o hábito católico da oração, a bíblia e a base de vida católica; em volta do catolicismo, a família cármica dos antepassados e o corpo casulo do espírito. Note-se que, além desses elementos da ordem do imaginário, circulam outros, como o livro do Bhagavad-gita, todos os livros sagrados e a Nova Era, a referência à Legião da Boa Vontade e a Hare Krishna, dissociados de seus simbólicos respectivos. Pode-se reconhecer também a influência sincrética da $S$ na construção mais confiante e generosa da identidade religiosa pessoal de S15. Finalmente, sem decidir se a dupla filiação grupal e o duplo simbólico configuram ou não duplicidade de identidade religiosa, é possível perceber a convergência dos processos de formação pessoal e psicossocial da identidade.

\section{Discussão}

Os depoimentos apresentados como ilustração das modalidades de trânsito religioso das entrevistadas revelam que a identidade religiosa somente foi alterada quando se relacionou com a categorização e a prototipificação grupal, isto é, quando o grupo de pertença anterior foi contraposto ao novo grupo de pertença e quando se contrapôs um protótipo a outro. Quando ao grupo de pertença, ou ao protótipo anterior, foi simplesmente acrescentado um outro grupo ou protótipo, não se alterou a identidade religiosa, mas tão somente ampliou-se o leque de identidades da pessoa, como em PL3. Um caso, o de SI5, ilustrou a duplicidade da pertença e da prototipificação, o que impediu estabelecer a manutenção ou a mudança da identidade religiosa. Os depoimentos revelam também a dinâmica motivacional predominantemente cognitiva (PL1) ou afetiva (PL 4) das entrevistadas, mesmo no caso em que o novo grupo de pertença e o novo protótipo não substituem os anteriores (PL 3). Conforme esperado pela teoria da identidade social, há paralelo estrito entre categorização e prototipicalidade. A autoprototipicalidade, medida de realização do protótipo pela pessoa individual, foi apresentada por PL1 e por S15.

O papel conferido à pertença grupal na formação da identidade deve ser completado pela verificação do arranjo simbólico ou imaginário que cada pessoa faz. Simbólica foi denominada a estruturação de elementos múltiplos ao redor de um eixo de significação; imaginária foi denominada a estruturação segundo a recondução ao mesmo de múltiplos elementos. Nos casos ilustrativos, encontrou-se consumada a estruturação simbólica em PL1, com a substituição de um simbólico por outro, e em PL 3, com o acréscimo de um simbólico a outro. Encontrou-se em curso a estruturação simbólica em PL 4, com a tendência a substituir uma articulação religiosa a outra. A estruturação imaginária, em que os elementos não se tornam interdependentes, mas se agrupam por semelhança, foi encontrada em S15, que vai e volta de uma referência religiosa a outra. Contudo, ao redor da estruturação simbólica de PL1, PL3 e PL4 comparecem, evocados por assimilação, elementos múltiplos, seja da primeira religião (PL1 e PL4), seja de ambos os sistemas simbólicos que atraem um do outro esses elementos (PL3).

A existência confronta a pessoa com referências múltiplas e díspares. As formações materiais, psíquicas e psicossociais resultam como amálgamas de muitos componentes. O sincretismo, que se refere a algumas formas dessa amalgamação, é inevitável. Em princípio, o sincretismo pode ser positivo ou negativo, segundo amplia ou coarcta o potencial humano. 
Historicamente, o termo, aplicado às formações culturais da religião, tem sido visto em sua vertente negativa. Com Stewart e Shaw (1994), Sanchis $(1994,1995,2001)$ e outros é, contudo, possível acompanhar composições sincréticas positivas no campo religioso, inclusive no campo do psiquismo, no qual situamos a questão da identidade. As entrevistas de ilustração mostraram a melhoria psicológica e psicossocial advinda da interação com outra religião ou filosofia (PL1, 4 e 3) ou, simplesmente, com uma cultura não ocidental (S15). Essa melhoria corresponde a ampliação e positivo desenvolvimento da identidade religiosa.

Com isso, não qualificamos o sincretismo como automaticamente conducente à expansão da identidade, mas tampouco o desqualificamos automaticamente, como tem sido o costume. A discussão dos processos de formação da identidade religiosa ficaria, no entanto, inconclusa se de todo não coincidissem os encaminhamentos psicossociais e os encaminhamentos pessoais na constituição dessa identidade. As entrevistas examinadas demonstraram que a formação da identidade psicossocial anda de par com a formação da identidade pessoal mediante a estruturação simbólica. Nos casos em que a pessoa passou a pertencer a um grupo por oposição ao grupo anterior, verificou-se reestruturação de ordem simbólica dos elementos cognitivos, afetivos e de ação da pessoa. No caso em que a pessoa agregou-se a mais de um grupo, verificou-se a aquisição de mais um simbólico, sem a perda do primeiro e sem o abandono do primeiro grupo. Finalmente, no caso em que não se consegue perceber o abandono de um grupo por outro, tampouco se percebe a substituição do primeiro simbólico por um segundo.

No pluralismo contemporâneo que oferece aos brasileiros, sem ascendência japonesa, a oportunidade de formação de uma identidade associada às 'novas religiões' distinguemse, pois, tanto os processos psicossociais de pertença a um novo grupo como os processos psicológicos de estruturação simbólica ou imaginária de novos elementos. Não é possível ajuizar a transformação da identidade religiosa anterior numa nova identidade religiosa, sem averiguar se o novo grupo de pertença é um outro grupo, que se contrapõe ao antigo, ou é mais um grupo, que se acrescenta ao anterior. Na pesquisa completa, de que se deu aqui apenas uma amostra das várias modalidades de trânsito religioso, mais de uma vez foi possível constatar, principalmente entre os filiados à $\mathrm{S}$, que o novo grupo de pertença é de natureza filosófica e/ou social, ao passo que o grupo anterior é de natureza religiosa. Nesses casos, não se pode falar de transformação da identidade religiosa psicossocial, e menos ainda de conversão.

Mas isso não basta. A pessoa que passa a fazer parte de um outro grupo religioso, filosófico, ou de outra natureza, elabora essa participação, seja como atividade psíquica subseqüente seja como atividade psíquica antecedente, freqüente em pessoas que estão em processo de busca. Essa elaboração pode ser uma reorganização dos múltiplos elementos, antigos e novos, ao redor de um novo eixo de significação, e nesse caso temos uma elaboração simbólica, que substitui o simbólico anterior de natureza religiosa ou outra. Mas a elaboração pode também ser um rearranjo dos múltiplos elementos no sentido de reprodução do mesmo, e nesse caso temos uma elaboração imaginária que assimila os elementos novos ao eixo simbólico anterior, de qualquer natureza. Só se poderá, então, falar de transformação da identidade religiosa ou de conversão no caso de convergirem o processo de filiação a um grupo que contrasta com o anterior enquanto grupo religioso e o processo de elaboração simbólica dos novos componentes de ordem cognitivo-afetiva e comportamental propostos.

\section{Referências}

Cassidy, C. \& Trew, K. (1998). Identities in Northern Ireland: A multidimensional approach. Journal of Social Issues, 54(4), 725-740.

Ellemers, N., Spears, R. \& Doosje, B. (2002). Self and social identity. Annual Review of Psychology, 52,161-186.

Frable, D.E.S. (1997). Gender, racial, ethnic, sexual, and class identities. Annual Review of Psychology, 48, 139-162.

Hervieu-Léger, D. (1998). The transmission and formation of socioreligious identities in Modernity: An analytical essay on the trajectories of identification. International Sociology, 13, 213-228.

Hoornaert, E. (1995). As igrejas cristãs no campo religioso latinoamericano e caribenho: Deslizamentos, apreensões, compromissos. Em E. Hoornaert (Org.), História da Igreja na América Latina e no Caribe. 1945-1995 (pp. 17-38). Petrópolis/São Paulo: Vozes/Cehila.

Kaufmann, P. (1993). Verbetes "imaginaire", "réel", "signifiant", "symbolique". Dictionnaire encyclopédique de psychanalyse. Le legs de Freud et Lacan. Paris: Bordas.

Lacan, J. (1966). Le stade du miroir comme formateur de la fonction du Je. Ecrits I. Paris: Seuil, 89-97.

Laplanche, J. \& Pontalis, J.-B. (1995). Vocabulário da psicanálise. (P. Tamen, Trad.) São Paulo: Martins Fontes, $2^{\mathrm{a}}$ ed. (Trabalho Original publicado em 1982).

Matsuno, J. (1974). Other religious organizations. Em I. Hori, F. Ikado, T. Wakimoto \& K. Yanagawa (Orgs.), Japanese religion. A survey by the Agency of Cultural Affairs (pp. 225-231). Palo Alto, CA: Kodansha.

Miyazaki, K. (2000). A fé dos Kakure Kirishitan que sobrevive na atualidade. Trabalho apresentado no II Simpósio Internacional de Cultura Luso-nipo-brasileira. São Paulo, SP.

Mucchielli, R. (1991). Les méthodes qualitatives. Paris: Presses Universitaires de France.

Murakami, S. (1980). Japanese religion in the Modern Century. Tokyo: University of Tokyo Press.

Negrão, L. N. (1997). Refazendo antigas e urdindo novas tramas. Religião e Sociedade, 18(2), 63-74

Oakes, P., Hasiam, S.A. \& Turner, J. C. (1998). The role of prototypicality in group influence and cohesion: Contextual variation in the graded structure of social categories. Em S. Worchel, J.F.Morales, D.Paez \& J.-C. Deschamps (Orgs.), Social identity. International perspectives (pp. 75-92). London: Sage.

Paiva, G.J. de (1999). Imaginário, simbólico e sincrético: Aspectos psicológicos da filiação a novas religiões japonesas. Psicologia: Reflexão e Crítica, 12(2), 521-535.

Paiva, G.J. de (2001). Cristo in Giappone: Rive e derive del cattolicesimo nella letteratura di Endo Shusaku. Em M. Aletti \& G. Rossi (Orgs.), L'illusione religiosa: Rive e derive (pp. 217-230). Torino: Centro Scientifico Editore.

Paiva, G.J. de, Faria, D.G., Gomes, D.M., Gomez, M.L.T., Lopes, R., Nunes, L.C., Verdade, M.M. \& Zangari, W. (2000). Processos 
psicológicos da conversão religiosa: Imaginário e simbólico, categorização e prototipicalidade. Psicologia Clínica, 12(2), 151-169.

Reid, D. (1991). New sine. The cultural shaping of japanese christianity, Berkeley, CA: Asian Humanities Press.

Sanchis, P. (2001). Religião, religiões... Alguns problemas do sincretismo no campo religioso brasileiro. Em P. Sanchis (Org.), Fiéis \& cidadãos. Percursos de sincretismo no Brasil (pp. 9-57). Rio de Janeiro: Editora da Universidade Estadual do Rio de Janeiro.

Stewart, C. \& Shaw, R. (Orgs.). (1994). Syncretism/anti-syncretism. The politics of religious synthesis. London: Routledge.

Tajfel, H. (1972). La catégorisation sociale. Em S. Moscovici (Org.). Introduction à la Psychologie Sociale (Vol.1, pp. 271-300). Paris: Larousse.
Tajfel, H. (1978). Differentiation between social groups: Studies in the social psychology of intergroup relation. London: Academic Press.

Turner, J.C. (1984). Social identification and psychological group formation. Em H.Tajfel (Org.). The social dimension (Vol. 1, pp. 519-538). Cambridge/Paris: Cambridge University Press/ Edition de la Maison des Sciences de l'Homme.

Turner, J.C. \& Oakes, P.J. (1986). The significance of the social identity concept for social psychology with reference to individualism, interactionism and social influence. British Journal of Social Psychology, 25(3), 237-252.

Recebido em 25.05.2003

Primeira decisão editorial em 18.02.2004

Versão final em 12.03.2004

Aceito em 25.03.2004 